\title{
El archivo: su rol como memoria e identidad ciudadana
}

\author{
Norma Catalina Fenoglio \\ Escuela de Archivología, Facultad de Filosofía y Humanidades, \\ Universidad Nacional de Córdoba, Argentina \\ norma.cfenoglio@yahoo.com.ar
}

\section{Resumen}

En los últimos años, los archivos municipales han acrecentado su protagonismo y cobra fuerza su rol como evidencia de la identidad de los ciudadanos y sustento de la memoria individual y colectiva del pueblo. En este trabajo se reflexiona acerca de los roles del archivo y su relación con las tareas técnicas del archivero, con el valor de los documentos y con la necesidad de políticas de acceso para favorecer el uso de la información para diferentes tipo de usuarios.

Palabras clave: archivo, identidad, memoria, documento, política de acceso

\section{Abstract}

In the last years the archives have increased their importance and their role as evidence of the identity of citizens and support of the individual and collective memory of the people.

In this paper, we reflect the roles and their relations with the technical tasks of the archivist or the records manager, the value of the documents and the need for access policies to promote the use of information for different types of users.

Key words: archives, identity, memory, document, access policy 


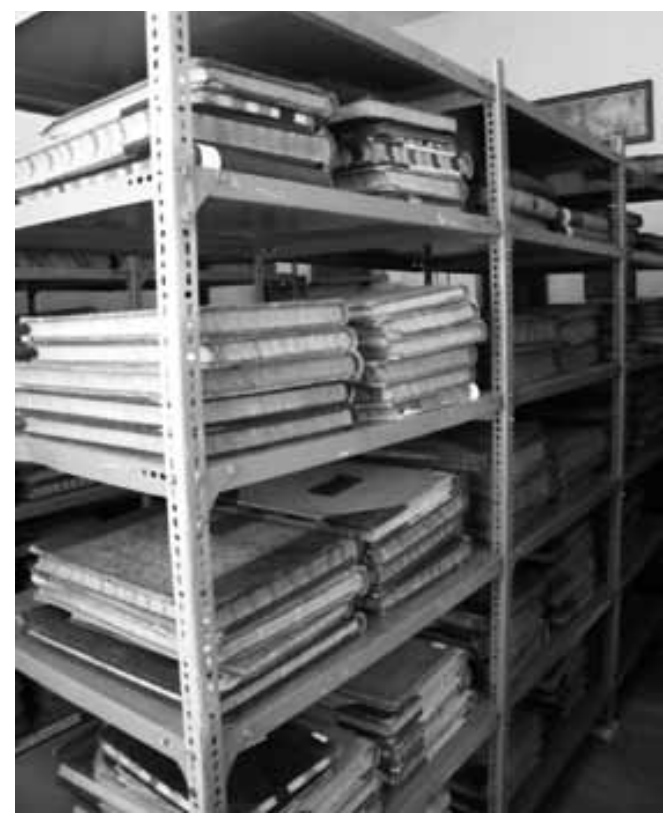

\section{Introducción}

Los municipios, ayuntamientos, alcaldías o comunas - de acuerdo con la denominación de cada región- son la base de la pirámide institucional del país, desde el punto de vista político. En los últimos años su misión se ha ampliado al incorporarle nuevos roles económicos, sociales, culturales así como políticas orientadas a profundizar la democracia, el desarrollo y la inclusión. Los archivos municipales, en consecuencia, también han acrecentado su rol. Así, además de custodiar los documentos producidos como resultado de la gestión de cada una de sus áreas, se han convertido en:

- Instrumento básico de administración; porque gracias a ellos se realizan muchos procesos y funciones operacionales.

- Herramienta esencial en cuanto a eficacia, transparencia y economía administrativa porque facilitan el acceso a las experiencias pasadas de la institución, incluidos éxitos y fracasos, 
asimismo, proponen precedentes cuando surgen cuestiones similares a dichas experiencias.

- Memoria institucional puesto que son fuente única de información sobre iniciativas, programas, medidas y procedimientos anteriores, al tiempo que preservan datos útiles para planificar inteligentemente el futuro, sobre la base de la experiencia adquirida en el pasado.

- Prueba de los derechos y las prerrogativas de los ciudadanos porque contienen material que demuestra sus actuaciones ante los funcionarios.

- Fuente para la historia local y regional; pues constituyen el patrimonio documental de la población, ya que contienen información de suma utilidad para la historia de las instituciones, de la localidad, de la región, de la provincia e incluso de la nación, para estudios sociales, políticos, económicos, sanitarios y de diversa índole.

- Evidencia de la identidad de los ciudadanos porque en los documentos se comprueba qué, quién, cómo y cuándo lo hizo.

- Sustento de la memoria individual y colectiva del pueblo.

El objetivo de este trabajo es reflexionar acerca de los roles de memoria y de identidad del archivo municipal y su relación con las tareas técnicas del archivero, con el valor de los documentos y con la necesidad de políticas de acceso para favorecer el uso de la información para diferentes tipo de usuarios.

\section{Archivo, documentos y acceso}

El archivo $^{1}$ se ha definido de numerosas maneras por diversos autores y desde diferentes disciplinas, por ejemplo: "Institución o sistema

\footnotetext{
${ }^{1}$ Siguiendo la sugerencia del ICA se utiliza la palabra Archivo con mayúscula inicial para designar a la institución y en minúsculas cuando se refiere al conjunto de documentos.
} 
responsable de las funciones integradas en la gestión de documentos y en la administración de Archivos de una organización" (Antonia Heredia Herrera);" "lugar de la memoria donde guardar los más ocultos secretos" (Alonso de Castillo); "cementerio de documentos desde donde los muertos gobiernan a los vivos" (Jorge Sinte); "memoria organizada del quehacer cotidiano de cualquier persona u organización" (Archivo Municipal de Ixtlahuaca), "5ranero de la historia y arsenal de la administración" (Charles Braivant).

Estas definiciones tienen relación directa con la perspectiva desde la cual se las observe. En este caso, interesa el enfoque del valor de los documentos, entendido como cualidad o conjunto de ellas que determinan el grado de utilidad de un documento de archivo para satisfacer las necesidades o proporcionar seguridad o tranquilidad, tanto a la entidad productora como a la sociedad en general. Por eso nos sentimos más cerca del concepto de Manuel Vázquez Murillo quien definió archivo como

la institución o el órgano de una institución que conduce la política de la gestión y guarda de los documentos y su servicio a los usuarios como recurso y patrimonio de sus creadores, de los ciudadanos y de las comunidades municipal, provincial o nacional, según su jurisdicción". ${ }^{6}$

En cuanto a su contenido -su fondo documental-, los archivos municipales dan testimonio y prueban la acción de las diferentes áreas del municipio: gobierno, salud, educación, cultura, obras públicas, acción social, recursos humanos, catastro, etcétera, con documentos que tienen distintos valores, tanto a nivel primario como secundario de acuerdo con el tipo de usuario que los requiera. Es decir, un documento

${ }^{2}$ Heredia Herrera, Lenguaje y vocabulario archivísticos, p. 46.

${ }^{3}$ Alberch Fugueras y Cruz Mundet, La aventura de la información, p. 206.

${ }^{4}$ Ibid., p. 208.

${ }^{5}$ Véase https://www.facebook.com/ArchivoMunicipalDeIxtlahuaca

${ }^{6}$ Vazquez Murillo, Administración de documentos y archivos, p. 70. 
de archivo puede tener valor administrativo (primario) para la entidad productora - en este caso la municipalidad-, y valor testimonial (secundario) para un investigador externo. Cabe recordar que el valor del documento es lo que determina el tiempo y el lugar de conservación.

Si entendemos a los documentos como prueba -tanto administrativa, como legal, técnica o de los derechos de los ciudadanos involucrados directa o indirectamente con la gestión municipal-, deben estar organizados para que puedan mostrarse. En cuanto a la organización nos referimos a su identificación, clasificación, descripción, ordenación, evaluación y selección, para que sean accesibles al usuario, sea interno o externo y pueda encontrarse la información que se necesita o interesa. ${ }^{7}$ Para llevar a cabo estos procesos técnicos existen teorías, reglas, principios, métodos y criterios, los cuales deben adecuarse a la tipología de los documentos, a la naturaleza de las series y a la legislación que se disponga. No detallaremos en qué consisten para no desviarnos del objetivo de este trabajo; sólo haremos algunas reflexiones en relación al acceso, por ser uno de los temas primordiales a tener en cuenta al organizar un archivo, porque su fin básico es servir los documentos a los usuarios.

En los últimos años se asentó con fuerza y como derecho democrático el acceso a la información relacionándolo con la transparencia administrativa y el gobierno abierto. El derecho de acceso a los documentos, definido por el Grupo de Trabajo sobre el Acceso del Comité de Buenas Prácticas y Normas del Consejo Internacional de Archivos como "la disponibilidad de los documentos para ser consultados como resultado tanto de una autorización legal como de la existencia de instrumentos de descripción", ${ }^{8}$ sitúa al usuario en el centro de las preocupaciones y de las actividades del archivista y hace que los archivos sean entendidos y utilizados como fuentes de información para cualquier tipo de investigación. Se trata de un derecho de vital importancia porque procura la transparencia

${ }^{7}$ Fenoglio, Norma y Gloria Bustos, "Archivos: memoria e identidad", p. 79. ${ }^{8}$ International Council on Archives. Committee on Best Practices and Standards. Working Group On Access, Principles of Access to Archives, p. 3. 
en el accionar del aparato estatal en general y del municipal en particular y contribuye a que disminuya la corrupción debido a que implica un mayor control del proceder de los funcionarios públicos. En la medida en que mejora el acceso a la información se facilita la defensa de derechos fundamentales individuales y colectivos, lo cual se traduce en el fortalecimiento de la democracia.

\section{Archivos, memoria e identidad}

Archivos y memoria son términos relacionados con mucha frecuencia. Esto se debe, quizá, al concepto de lieux de mémoire (lugares de memoria o sitios de memoria) acuñado por Pierre Nora. No obstante, es un concepto que debe tomarse con cuidado, por cuanto, como afirma el mismo reconocido historiador y filósofo francés:

La memoria es el recuerdo de un pasado vivido o imaginado. Por esa razón, la memoria siempre es portada por grupos de seres vivos que experimentaron los hechos o creen haberlo hecho. La memoria, por naturaleza, es afectiva, emotiva, abierta a todas las transformaciones, inconsciente de sus sucesivas transformaciones, vulnerable a toda manipulación, susceptible de permanecer latente durante largos periodos y de bruscos despertares. La memoria es siempre un fenómeno colectivo, aunque sea psicológicamente vivida como individual. [...] La memoria depende en gran parte de lo mágico y sólo acepta las informaciones que le convienen. ${ }^{9}$

De este párrafo se pueden inferir diferencias fundamentales entre memoria y archivo. En cuanto a las características básicas que deben tener los archivos (documentos) son: autenticidad, integridad y

${ }^{9}$ Corradini, Luisa, "No hay que confundir memoria con historia, dijo Pierre Nora". 
fiabilidad de la información que contienen, así como valor probatorio, lo que no coincide con lo imaginado, lo mágico, ni con la vulnerabilidad a la que se refiere Nora.

Desde otro punto de vista, Hilary Jenkinson también asignó a los archivos un rol de "memoria artificial", con el razonamiento de que los documentos sirven para que el archivista, o el administrador, "no dependa de su propia memoria, sino que encuentre un resumen de todo lo que se ha hecho en el pasado sobre ese asunto en sus ficheros". ${ }^{10}$ De ese modo, de acuerdo con este autor, el documento escrito alivia la memoria del administrador porque "recordar realizando un registro significa realmente que después se puede olvidar con más seguridad"11 y la intención de la producción de documentos es dejar constancia de algo al futuro. Paralelamente, siguiendo este criterio, el archivero adquiere el rol de "cocreador" de la memoria colectiva.

Por su parte, Angelika Menne Haritz se refiere a la memoria como un fenómeno social, no técnico, y afirma:

La memoria no es un objeto, como un libro o una grabación, que pueden ser almacenados. Ambos son útiles a la hora de hacer posible la memoria, pero no pueden reemplazarla. La memoria sucede cuando es necesitada. Utiliza toda clase de fuentes disponibles que puedan contar su historia. Todas ellas son aprovechadas para los propósitos de la memoria según el caso, y la atención no está puesta solamente en lo que está presentado y ofrecido como fuente. ${ }^{12}$

Para esta reconocida profesional alemana, los archivos no almacenan memoria sino que ofrecen la posibilidad de crearla. Considera que la función

${ }^{10}$ Jenkinson, Manual of Archive Administration, pp.152-153, citado por Piggott, Michael, "Archivos y memoria", p. 407.

${ }^{11}$ Ibid., p. 430.

12 Angelika Menne-Haritz, "Access-the Reformulation of an Archival Paradigm", p. 58. 
de los archivos es prevenir la amnesia porque nos permiten construir memoria, refinarla, corregirla o reasegurarla cuando es necesario, y que

el principal servicio que ofrecen los archivos a las sociedades globales emergentes es el acceso al material en crudo para la memoria y de ese modo garantizan la capacidad de construir y dar forma a la memoria de una manera que nos ayude a comprender los problemas del presente y prepararnos para el futuro". ${ }^{13}$

Coinciden con esta apreciación Ramón Alberch Fugueras y José Ramón Cruz Mundet cuando afirman que "los documentos obrantes en los archivos constituyen los elementos fundamentales para la recuperación y la preservación de la memoria histórica", ${ }^{14}$ pero "el archivo solo no representa la memoria corporativa de una organización", como asevera Michael Piggott. ${ }^{15}$ Del mismo modo, la memoria -tanto individual como colectiva- está condicionada por la historia vivida; esto significa que la memoria trasciende el archivo, por su relación con el pasado y también con el presente, así como por su dimensión social y colectiva, que adquirió relevancia -especialmente en la segunda mitad del siglo $\mathrm{xx}^{-}$, , con relación a hechos traumáticos vividos en algunos países por algunos grupos sociales.

Muy interesante es, al respecto, la opinión de Pierre Nora quien, al referirse a la misión de los archivos en la sociedad contemporánea, distingue tres edades: la edad notarial y utilitaria, la edad histórica y documental y la edad de la memoria y la identidad, y agrega:

El archivo es, en efecto, la interfase, el lugar de encuentro y de conflicto entre dos formas de nuestra memoria contemporánea: la memoria vivida y la memoria documentada,

${ }_{13}^{13}$ Ibid., p. 59.

${ }^{14}$ Alberch Fugueras y Cruz Mundet, jArchívese! Los documentos del poder. p. 150.

${ }^{15}$ Piggott, "Archivos y memoria", p. 428. 
la memoria directa y la memoria indirecta, inmediata y mediata, la memoria del testimonio y la de la historia científica, la memoria viviente y la memoria reedificada, memoria caliente y memoria fría. ${ }^{16}$

En cuanto al documento, Jacques Le Goff afirma que "no es un material objetivo, inocente y puro, sino que expresa el poder que ejerce la sociedad del pasado sobre la memoria y sobre el futuro: es el documento lo que permanece". ${ }^{17}$

Por su parte, Terry Cook sostiene que los archivistas han pasado de ser guardianes pasivos del resultado documental que dejaron los productores a convertirse en activos partícipes de la creación del patrimonio archivístico, esto es, han pasado de custodiar, de forma supuestamente imparcial, los documentos heredados, a convertirse en agentes mediadores, conscientes de su propia dimensión histórica en el proceso de creación de los archivos y la formación de la memoria. ${ }^{18}$

En este sentido, el desarrollo del trabajo archivístico técnico depende, en buena medida de las decisiones que se tomen en el proceso de evaluación, de ahí que la selección de los documentos considerados sin valor secundario sea frecuentemente objeto de polémica entre archivistas e historiadores, quienes se encuentran -muchas veces- en polos opuestos en el proceso de formación del patrimonio documental $y$, por ende, de la memoria. En efecto, mientras los primeros consideran necesario aplicar criterios de selección documental con miras a controlar la cantidad de documentos a conservar dando una solución institucional a diversos problemas derivados de su producción, los historiadores, -en general-, pugnan por la conservación del mayor número de documentos para garantizar la integridad de la información de acuerdo con sus fines de investigación.

\footnotetext{
${ }^{16}$ Nora, "Missions et enjeux des archives dans les sociétés contemporaines", p. 48. ${ }^{17}$ Le Goff, History and Memory, citado por Cox, Richard J., "La valoración como un acto de memoria", p. 59.

${ }^{18}$ Cook, Interacción entre la teoría y la práctica archivística, p. 18.
} 
En cuanto a la problemática de la identidad, hemos visto que Pierre Nora une memoria e identidad en la que considera la tercera edad de los documentos, la cual interesa "a todos y a nadie"; 19 y agrega: "hemos convertido al archivo en depositario de nuestra identidad. De allí su carga afectiva y emocional que nunca ha sido tan grande". ${ }^{20}$

Desde un punto de vista estrictamente técnico, si hacemos un análisis comparativo dentro de las series documentales existentes en un mismo archivo, a lo largo de un periodo más o menos prolongado, cualquiera que sea la serie, seguramente observaremos que para un mismo resultado el trámite fue sufriendo modificaciones, tanto de forma como de fondo: ya no encontramos - $\mathrm{O}$ muy raramente- ${ }^{-}$solicitudes manuscritas; la terminología utilizada ha cambiado, los requisitos se han multiplicado, el formato se ha normalizado, el soporte muchas veces ha pasado de papel a digital. Estos "signos" que denominamos caracteres externos al documento son el resultado de un cambio -o de una evolución- de la mentalidad del administrador, influido por el resto de la sociedad y, sin lugar a dudas, por la globalización, definida como "conjunto de procesos de homogeneización y, a la vez, de fraccionamiento articulado del mundo, que reordena las diferencias y las desigualdades sin suprimirlas". ${ }^{21}$

Este hecho obliga a preguntarnos: ¿la globalización está modificando la identidad individual? Cada reforma de un tipo documental ¿fue el resultado de un estudio para mejorar el procedimiento, teniendo en cuenta al usuario y su identidad o representan la identidad propia del productor? Es un tema que merece ser analizado en profundidad.

Hace unos años al plantear la influencia de la globalización en los criterios de valoración de los documentos en los archivos municipales afirmábamos:

La carencia de elementos para identificar hechos del pasado llevará a globalizar la información de cada archivo

${ }^{19}$ Nora, "Missions et enjeux", p. 48.

${ }^{20}$ Idem.

${ }^{21}$ García Canclini, Néstor, La globalización imaginada, pp. 48-49. 
y, con ello, se perderá lo individual de cada uno, como miembros que participan en una comunidad cultural única e irrepetible que puede aportar su singularidad al mundo globalizado. El dinero y el tiempo son valores variables; la identidad es un valor permanente". ${ }^{22}$

El debate sigue pendiente. Por ahora, es indudable que, al momento de organizar un archivo, debemos tener en cuenta estas transformaciones y dejar constancia de ellas, porque son, precisamente, la evidencia de la mentalidad y, por ende, de la identidad del productor.

\section{Palabras finales}

El desarrollo tecnológico de las últimas décadas, las innovaciones en los métodos de enseñanza, el interés por el planeamiento y prospección del desarrollo económico y social y el ritmo vertiginoso de los avances de las investigaciones en todos los campos, han creado nuevas necesidades de información y es así como periodistas, científicos, políticos y economistas se sumaron a los tradicionales usufructuarios de nuestros archivos, antes visitados sólo por historiadores.

Esta realidad propicia que, así como el archivo adquiere nuevos roles, las exigencias y las funciones de los archivistas aumenten, tanto en lo concerniente a la preservación del material como en la atención de los usuarios. En los archivos gubernamentales, particularmente en los municipales, la responsabilidad y el compromiso del archivero es fundamental porque al deber ético profesional se suma la responsabilidad política ante la sociedad que está involucrada en los documentos y la información que se destruirá o se conservará. Al respecto, Terry Eastwood, sostiene que en una sociedad democrática, el archivo debe "satisfacer la necesidad que tienen los ciudadanos de saber cómo se ha gobernado y, asimismo, permitirles llegar a

${ }^{22}$ Fenoglio, Norma, "Nuevos criterios de selección frente a la globalización". 
comprender el lugar que ocupan dentro de las comunidades de las que se consideran miembros". ${ }^{23}$

Este derecho a la información se relaciona tanto con la protección de los derechos individuales como con la defensa de la identidad y el valor de los documentos, con la memoria y la identidad de cada ciudad y de sus habitantes, tanto en lo individual como en lo colectivo, porque, como dice Wilfred Smith: "los archivos son un producto importante de la civilización, un recurso cultural, un elemento esencial de la herencia humana". ${ }^{24}$

${ }^{23}$ Eastwood, Terry, "La valoración archivística en las sociedades democráticas", p. 81.

${ }^{24}$ Smith, Wilfred I., "Archivos y cultura: un ensayo", p. 401. 


\section{Bibliografía}

Alberch Fugueras, Ramón y Cruz Mundet, José Ramón, jArchívese! Los documentos del poder. El poder de los documentos, Madrid, Comunicación, Alianza Editorial, 2002.

, La aventura de la información. De los manuscritos del mar Muerto al imperio Gates, Madrid, Alianza Editorial, 2004.

Cook, Terry, Interacción entre la teoría y la práctica archivística desde la publicación del manual holandés en 1898, Memorias del Congreso Internacional de Archivos, Beijing, 1996. Actas del Congreso del Internacional de Archivos en Pekín, 1996

Corradini, Luisa, "No hay que confundir memoria con historia, dijo Pierre Nora", en La Nación, sección Cultura, miércoles 15 de marzo de 2006, Buenos Aires, disponible en http://www.lanacion. com.ar/788817-no-hay-que-confundir-memoria-con-historia-dijopierre-nora

Cox, Richard J., "La valoración como un acto de memoria", en Tabula, Revista de Archivos de Castilla y León, núm. 6, Departamento de Biblioteconomía y Documentación, Universidad de Salamanca, Salamanca, 2003, pp. 51-73.

Eastwood, Terry, "La valoración archivística en las sociedades democráticas", en Tabula, Revista de Archivos de Castilla y León, núm. 6, Departamento de Biblioteconomía y Documentación, Universidad de Salamanca, Salamanca, 2003, pp. 75-85.

Fenoglio, Norma, "Nuevos criterios de selección frente a la globalización", en la ponencia presentada en las XI Jornadas de Archivistas de la Argentina, organizadas por la Dirección General de Cultura y Educación, Subsecretaría de Cultura de la Provincia de Buenos Aires (en Mar del Plata, Buenos Aires), del 19 al 21 de agosto de 1999.

, y Bustos, Gloria, "Archivos: memoria e identidad Disquisiciones desde la archivística y el análisis del discurso", en 
Revista del Archivo Nacional, San José, Costa Rica, enero a diciembre, 2008, año LXXII, núms.1-12, 2008, pp. 73-84.

García Canclini, Néstor, La globalización imaginada, México-Buenos Aires-Barcelona, Paidós, 1999.

Heredia Herrera, Antonia, Lenguaje y vocabulario archivísticos, algo más que un diccionario, Sevilla, Junta de Andalucía, Consejería de Cultura, 2011.

International Council on Archives, Committee on Best Practices and Standards, Working Group on Access, Principles of Access to Archives, Annual General Meeting, 2012.16, Brisbane, Australia 24, de agosto de 2012.

Menne-Haritz, Angelika, "Access-the Reformulation of an Archival Paradigm", en Archival Science, Netherlands, Kluver Academic Publishers, 2001, p. 57-82.

Nora, Pierre, "Missions et enjeux des archives dans les sociétés contemporaines”, en Comma 2003.2/3, ICA, París, 2003, pp. 47-49.

Piggott, Michael, "Archivos y memoria", en Archivos: Gestión de registros en sociedad, Col. Tendencias, 6, 3000 Informática, Cartagena, Ayuntamiento. Concejalía de Cultura, 2007, Cap. 12, pp. 405-441.

Smith, Wilfred I., "Archivos y cultura: un ensayo", en La administración moderna de archivos y la gestión de documentos: el prontuario RAMP, París, PGI-85/WS/32, 1985, pp. 401-413.

Vázquez Murillo, Manuel, Administración de documentos y archivos. Planteos para el siglo XXI, Buenos Aires, Alfagrama Ediciones, 2004. 